\title{
THE PREVALENCE OF UNHEALTHY SNACKING BEHAVIOUR AND ITS ASSOCIATION WITH INDIVIDUAL AND ENVIRONMENTAL FACTORS AMONG COLLEGE STUDENTS IN KUCHING, SARAWAK
}

\author{
Cheah Yong Xiang ${ }^{1 *}$ and Cheah Whye Lian ${ }^{1}$ \\ ${ }^{1}$ Department of Community Medicine and Public Health, Faculty of Medicine and Health Sciences, Universiti Malaysia \\ Sarawak, Malaysia. 94300, Kota Samarahan, Sarawak, Malaysia.
}

Corresponding author: Cheah Yong Xiang

E-mail: 20040004@siswa.unimas.my, drcheah@moh.gov.my

\begin{abstract}
Unhealthy snacking behaviour among young people is a growing public health concern because of its negative consequences on health. This study was to determine the prevalence of unhealthy snacking behaviour and its determinants among college students in Kuching. In this cross-sectional study, 12 colleges in Kuching were stratified into private and government colleges. Three private and three government colleges were selected through a stratified random sampling method. A total of 422 respondents (male 49.5\%, female 50.5\%) were recruited in this study. A selfadministered questionnaire was used to gather data regarding unhealthy snacking behaviour and its determinants (gender, food preferences, type of school and courses, taste-and-sensory perception, nutritional knowledge, perceived self-efficacy, and cost/price sensitivity, perceived parental control, easy accessibility, and media advertisements influence) among respondents. The survey was conducted online via e-mail/Whatsapp. Multiple binary logistic regression analysis was used to analyse the data. A quarter of the respondents $(24.6 \%)$ practised unhealthy snacking behaviour. More than half of the respondents (58.3\%) consumed unhealthy snacks one to three times per week. $A$ minority of the respondents (17.1\%) claimed that they did not consume any unhealthy snacks for the past month. The final model explained $15.7 \%$ of the total variance. Taste-and-sensory perception (Adjusted OR $=2.20,95 \% \mathrm{Cl}$ [1.55, 3.13], $p<0.001$ ) and nutritional knowledge (Adjusted OR $=1.48,95 \% \mathrm{Cl}[1.12,1.97), p<0.05)$ were positively associated with unhealthy snacking behaviour among respondents. The present study suggested the stakeholders concentrate on nutritional knowledge and taste-and-sensory perception among college students in future intervention development.
\end{abstract}

Keywords: Unhealthy snacking behaviour, Individual factors, Environmental factors, College students, Kuching, Sarawak.

\section{INTRODUCTION}

Most people perceived that snacks are small portion packaged, nutrient-poor, low-price foods, or beverages ${ }^{1,2}$, and snacking refers to consume energy outside of breakfast, lunch, and dinner ${ }^{3}$. Nevertheless, the definition of snacks was remaining inconsistent ${ }^{4}$, because the scientific consensus about what constitutes a snack does not exist ${ }^{5}$, either the snacks consumed between meals or the snacks consumed during the meal as a meal replacement ${ }^{6}$. By definition, snacks can be divided into unhealthy snacks and healthy snacks. Unhealthy snacks commonly referred to as nutrient-poor food or beverages that are high in calories, fat, sodium, and/or sugar, such as potato chips, crackers, pickles, cakes, ice-cream, chocolate, candy, sugar-sweetened beverages (SSBs), nuggets, sausages, and french fries ${ }^{3,7,8}$. In contrast, for healthy snacks, the first ingredient should be vegetable/fruit, dairy product, protein food, or a grain product that at least contains onehalf of whole grains by weight; or a combination food that contains at least a quarter cup of vegetable/fruit. Additionally, a healthy snack should also meet the nutrient guidelines for calories, sugar, sodium, and fats ${ }^{9}$.
Consuming unhealthy snacks has become a public health concern 10-12 because it has been discovered that it is one of the risk factors for metabolic syndrome and diet-related noncommunicable diseases (NCDs), particularly obesity, cardiovascular disease, diabetes, and hyperlipidemia 13-15. Mithra, Unnikrishnan, and Thapar et al. (2018) defined any individual that repeatedly consumed unhealthy snacks more than three times per week considered as unhealthy snacking behaviour ${ }^{16}$.

The college-going age population, mainly around 18-24 years old, is also called late-adolescents or young adults 17,18 . This period was associated with critical changes in physical, mental, emotional, social lifestyle, as well as eating behaviour ${ }^{19}$. Meanwhile, adolescents' lack of risk perception of NCDs 20,21 may lead to unhealthy snacking behaviours as a result of taste-and-sensory perception, nutritional knowledge, easy accessibility, and media pressure ${ }^{22}$. Therefore, the main purpose of this research was to determine the prevalence of unhealthy snacking behaviour and its associated factors among college students in Kuching. The implication of this study may provide advantages of concentrating on the significant determinants in 
the intervention programme on similar study populations in the future.

\section{METHODOLOGY}

\section{Participants and sampling}

In this cross-sectional study, we stratified 12 colleges in Kuching into private and government colleges. Next, we selected three private colleges (Asia Metropolitan College Kuching, International College of Advanced Technology Sarawak, and Limkokwing Institute of Creative Technology) and three government colleges (Kuching Vocational College, Kuching Community College, and Santubong Vocational College) through a stratified random sampling method within each stratum. With a 95\% confidence interval and 5\% precision level, anticipated population proportion for unhealthy snacking behaviour of 0.54 among college students ${ }^{16}$, and expected no more than $10 \%$ non-response, this study recruited a total of 422 college students (Malaysian and non-Malaysian) with active status in the selected colleges.

\section{Independent measures and instrument}

Previous research proposed an integrated theoretical framework based on social cognitive theory and the ecological model to easily understand the factors associated with eating behaviour among young people 22,23. Eating behaviour among young people was considered as a function of multiple levels of influence in that framework, which included individual, socialenvironmental, physical-environmental, and macrosystem influences. These influences can be divided into two domain: individual factors and environmental factors ${ }^{22-24}$.

In the present study, the domain of individual factors included socio-demographic characteristics (age, gender, the name of college, the type of college, and type of course), and psychosocial factors (food preferences, cost/price sensitivity, taste-and-sensory perception, nutritional knowledge, and self-efficacy). Meanwhile, the domain of environmental factors included social-environmental (perceived parental control on unhealthy snacks), physicalenvironmental (easy accessibility to unhealthy snacks), and macrosystem influences (media advertisements influence). The measures of these independent factors were separately discussed in the following paragraphs.

Socio-demographic characteristics: This part consisted of five questions, which included gender and age of the respondents, the course (sciences or non-sciences area), the food preference (vegetarian or non-vegetarian), the type of colleges (government or private), and the name of the college that they were studying.
Cost/price sensitivity: This measure consisted of two items, for example, "Because unhealthy snacks are less expensive, I eat them." A higher rating on this question corresponds to a stronger role of cost/price sensitivity in influencing unhealthy snacking behaviour.

Taste-and-sensory perception: This measure consisted of three items, for example, "Because unhealthy snacks are tasty and delicious, I eat them." A higher rating on this question corresponds to a stronger role of taste-andsensory in influencing unhealthy snacking behaviour.

Nutritional knowledge: This measure consisted of two items, for example, "Bubble tea is an unhealthy drink." A higher rating on this question corresponds to greater nutritional knowledge.

Perceived self-efficacy: This measure consisted of two items, for example, "I am confident that, if I wanted to, I could reduce consumption of certain unhealthy snacks." A higher rating on this question corresponds to greater self-efficacy.

Perceived parental control: This measure consisted of two items, for example, "My parents tell me how much unhealthy snacks I may consume." A higher rating on this question corresponds to greater parental control for consuming unhealthy snacks.

Easy accessibility: This measure consisted of three items, for example, "If I have access to unhealthy snacks at home, most probably I will eat these food items." A higher rating on this question corresponds to a stronger role of easy accessibility in influencing unhealthy snacking behaviour.

Media advertisements: This measure consisted of two items, for example, "Advertisement on TV or social media (Facebook, YouTube...) stimulates me to eat unhealthy snacks". A higher rating on this question corresponds to a stronger role of the media ads in influencing unhealthy snacking behaviour.

The questionnaire was taken from Yazdi Feyzabadi, Keshavarz Mohammadi, and Omidvar et. al (2017), and approved by them in 2019. It was then cross-culturally adapted and validated for the Malaysian college-going age population. In our pilot study, 51 college students participated, and the reliability (Cronbach alpha) of the cost/price sensitivity, taste-and-sensory perception, nutritional knowledge, perceived self-efficacy, perceived parental control, easy accessibility, and media advertisements constructs were $0.621,0.713,0.702,0.663,0.654$, 0.675 and 0.689 , respectively (greater than the acceptable cut-off point of 0.6 ), indicated an acceptable level of reliability ${ }^{25}$. 


\section{Dependent measures}

All respondents answered the frequency of intake of unhealthy snacks per week for the past month. Any individual that repeatedly consumes unhealthy snack more than three times per week for one month considered unhealthy snacking behaviour in this measure ${ }^{16}$.

\section{Data collection procedures}

To conduct research at the selected colleges, first, permission was obtained from the Chairman of Technical and Vocational Education Division, and the Director-General of the Department of Polytechnic and Community College Education Department, Ministry of Higher Education in Putrajaya. Next, approval was given by the Sarawak State Education Department for data collection in these colleges. Then, the appointments with the Head of each selected college were made. A brief introduction and the purpose of this study were explained to them separately. Afterwards, the link to the Google form was sent separately to the liaison officer of each college. Next, the liaison officers disseminated the link to the college students via e-mail or WhatsApp. The period for data collection started from February 2020 till June 2020.

\section{Statistical analysis}

The collected data were checked and coded. The respondents were classified into three groups based on the frequency of intake of unhealthy snacks, which were: unhealthy snacking behaviour (those who repeatedly consume unhealthy snacks more than three times per week), occasionally (those who consume unhealthy snacks 1-3 times per week), and none (those who consume unhealthy snacks 0 times per week). IBM Statistical Package for the Social Sciences (SPSS) software, Version 22 was used for data analysis. Simple binary logistic regression analysis was used to test hypotheses about the relationship between unhealthy snacking behaviour and its association with individual factors and environmental factors among respondents. The assumption of outliers, the relationship between the independent variables and the logit of the dependent variable, multicollinearity, and independent observation were checked. The association between each factor and outcome was analysed separately to identify which were the potential factors associated with unhealthy snacking behaviour. Those independent factors that showed the $p<$ 0.20 in the simple binary logistic regression analysis were shortlisted into the multiple binary logistic regression analysis. Next, the multiple binary logistic regression analysis was used to determine the factors associated with unhealthy snacking behaviour among college students. The Hosmer-Lemeshow goodness-of-fit statistic was used to evaluate the goodness-of-fit of the overall model. The sensitivity, specificity of the final model's prediction were checked with a classification table. The model's discriminatory capacity was examined using the Area under the ROC curve (AUC) analysis.

\section{RESULTS}

\section{Descriptive analysis of all variables}

A total of 427 questionnaires were distributed, 422 were returned $(98.8 \%$ response rate). Table 1 shows the socio-demographic characteristics of the respondents. The mean (SD) age was 19.69 $( \pm 1.47)$ years old, while the youngest was 18 years old, and the eldest was 29 years old. Most of them $(89.6 \%)$ were $18-21$ years old. Half of the respondents were females $(50.5 \%)$, and half were males $(49.5 \%)$. A little more than half of them (53.3\%) were studying in private colleges $(99$ students in science areas, 126 students in nonscience areas), and nearly half (46.7\%) were studying in government colleges (77 students in science areas, 120 students in non-sciences areas). There were slightly more than half of the college students (58.3\%) enrolled in non-science courses, while the rest were enrolled in science courses $(41.7 \%)$. However, the majority of college students $(80.8 \%)$ were non-vegetarians, while the rest were vegetarians (19.2\%).

Table 2 shows the mean scores of the main measures among the respondents. On the domain of individual factors, the taste-and-sensory perception $($ mean $=3.08, S D=0.86)$ got the highest mean score, followed with perceived selfefficacy $($ mean $=3.07, \mathrm{SD}=1.06)$, cost $/$ price sensitivity (mean $=3.01, \mathrm{SD}=0.99)$, and nutritional knowledge $($ mean $=2.65, \mathrm{SD}=0.89$ ). On the domain of environmental factors, the media advertisements influence (mean $=3.17$, SD $=1.03$ ) obtained the highest mean score, followed with easy accessibility (mean $=3.04, S D=0.92$ ), and perceived parental control (mean $=3.03$, SD $=0.86)$.

Table 3 reveals the prevalence of unhealthy snacking behaviour among the respondents. Nearly 1 in 5 of the college students (17.1\%) claimed that they did not consume any unhealthy snacks (0 times per week) for the past one month. Besides, more than half of college students (58.3\%) consumed unhealthy snacks occasionally (1 - 3 times per week). Moreover, there were a quarter of the college students (24.6\%) consumed unhealthy snacks repeatedly more than three times per week. 
Table 1: Sociodemographic characteristics of the respondents $(n=422)$

\begin{tabular}{|c|c|c|c|c|}
\hline & frequency & $(\%)$ & mean (SD) & \\
\hline Age (year) & & & $19.69(1.47)$ & $\begin{array}{l}\min =18 \\
\max =29\end{array}$ \\
\hline \multicolumn{5}{|l|}{ Gender } \\
\hline Female & 213 & $(50.5)$ & & \\
\hline Male & 209 & (49.5) & & \\
\hline \multicolumn{5}{|l|}{ School type } \\
\hline Government & 197 & $(46.7)$ & & \\
\hline Private & 225 & (53.3) & & \\
\hline \multicolumn{5}{|l|}{ Course } \\
\hline Sciences & 176 & (41.7) & & \\
\hline Non-sciences & 246 & (58.3) & & \\
\hline \multicolumn{5}{|l|}{ Food preference } \\
\hline Vegetarians & 81 & $(19.2)$ & & \\
\hline Non-vegetarians & 341 & $(80.8)$ & & \\
\hline
\end{tabular}

Footnote: $n$ = sample size, $S D=$ Standard deviation

Table 2: Mean scores of the main measures among the respondents. $(n=422)$

\begin{tabular}{|c|c|c|}
\hline & mean & (SD) \\
\hline \multicolumn{3}{|l|}{ Individual factors } \\
\hline Taste and sensory perception & 3.08 & $(0.86)$ \\
\hline Perceived self-efficacy & 3.07 & (1.06) \\
\hline Cost/price sensitivity & 3.01 & $(0.99)$ \\
\hline Nutritional knowledge & 2.65 & $(0.89)$ \\
\hline \multirow{2}{*}{\multicolumn{3}{|c|}{ Environmental factors }} \\
\hline Social-environmental: & & \\
\hline $\begin{array}{l}\text { Perceived parental control } \\
\text { Physical-environmental: }\end{array}$ & 3.03 & $(0.86)$ \\
\hline Easy accessibility & 3.04 & $(0.92)$ \\
\hline Macro-system: & & \\
\hline Media advertisements influence & 3.17 & $(1.03)$ \\
\hline
\end{tabular}

Table 3: The prevalence of unhealthy snacking behaviour among respondents $(n=422)$

\begin{tabular}{|c|c|c|}
\hline & frequency & $(\%)$ \\
\hline None & & \\
\hline 0 times per week & 72 & (17.1) \\
\hline $\begin{array}{l}1-3 \text { times per week } \\
\text { Unhealthy snacking behaviour }\end{array}$ & 246 & $(58.3)$ \\
\hline more than three times per week & 104 & (24.6) \\
\hline
\end{tabular}

\section{Simple binary logistic regression analysis}

The assumption of outliers was tested using Mahalanobis distance statistics, and none of the critical values of the chi-square distribution fell below the threshold value of $p<0.001$ (the smallest value was 0.0024 ), indicated that there's no outlier ${ }^{26}$. The Box-Tidwell procedure ${ }^{27}$ was used to test the linearity of the independent variables to the logit of the dependent variable. A Bonferroni correction 26 was applied to all independent variables in the model, and statistical significance was accepted when $p<$ 0.0042 . The results revealed that the relationship between the independent variables and the logit of the dependent variable was linear. The Pearson correlation matrix between each pair of independent variables revealed that the highest correlation, with a value of 0.527 (below the cutoff point of 0.8 ) ${ }^{28}$, is between taste-and-sensory perception and media advertisement influence, indicated that no suspected multicollinearity between independent variables existed ${ }^{29}$. DurbinWatson value is 1.615 (between 1.5-2.5), indicated that the observations did not come from repeated measurements or matched data ${ }^{30}$.

Table 4 shows the simple binary logistic regression analysis for the association between each independent variables with unhealthy snacking behaviour among the respondents. Two predictors of unhealthy snacking behaviour were found significant $(p<0.05)$. The media advertisements influence $x^{2}(1, \mathrm{n}=422)=19.429, \mathrm{p}<0.001, \mathrm{OR}=$ $1.663,95 \% \mathrm{Cl}[1.314,2.106]$, and the taste-andsensory perception $x^{2}(1, n=422)=35.544, p<$ 
0.001, OR $=2.338,95 \% \mathrm{Cl}[1.732,3.156]$ were positively associated with unhealthy snacking behaviour. Nevertheless, those predictors of unhealthy snacking behaviour with $p<0.20$ in simple binary logistic regression were selected for subsequent multiple binary logistic regression analyses. Therefore, three individual factors (food preference, taste-and-sensory perception, nutritional knowledge) and three environmental factors (media advertisements influence, perceived parental control, and easy accessibility) with $\mathrm{p}<0.20$ were then included for further multiple binary logistic regression analysis.

Table 4: Simple binary logistic regression analysis for the association between each independent variable with unhealthy snacking behaviour $(n=422)$

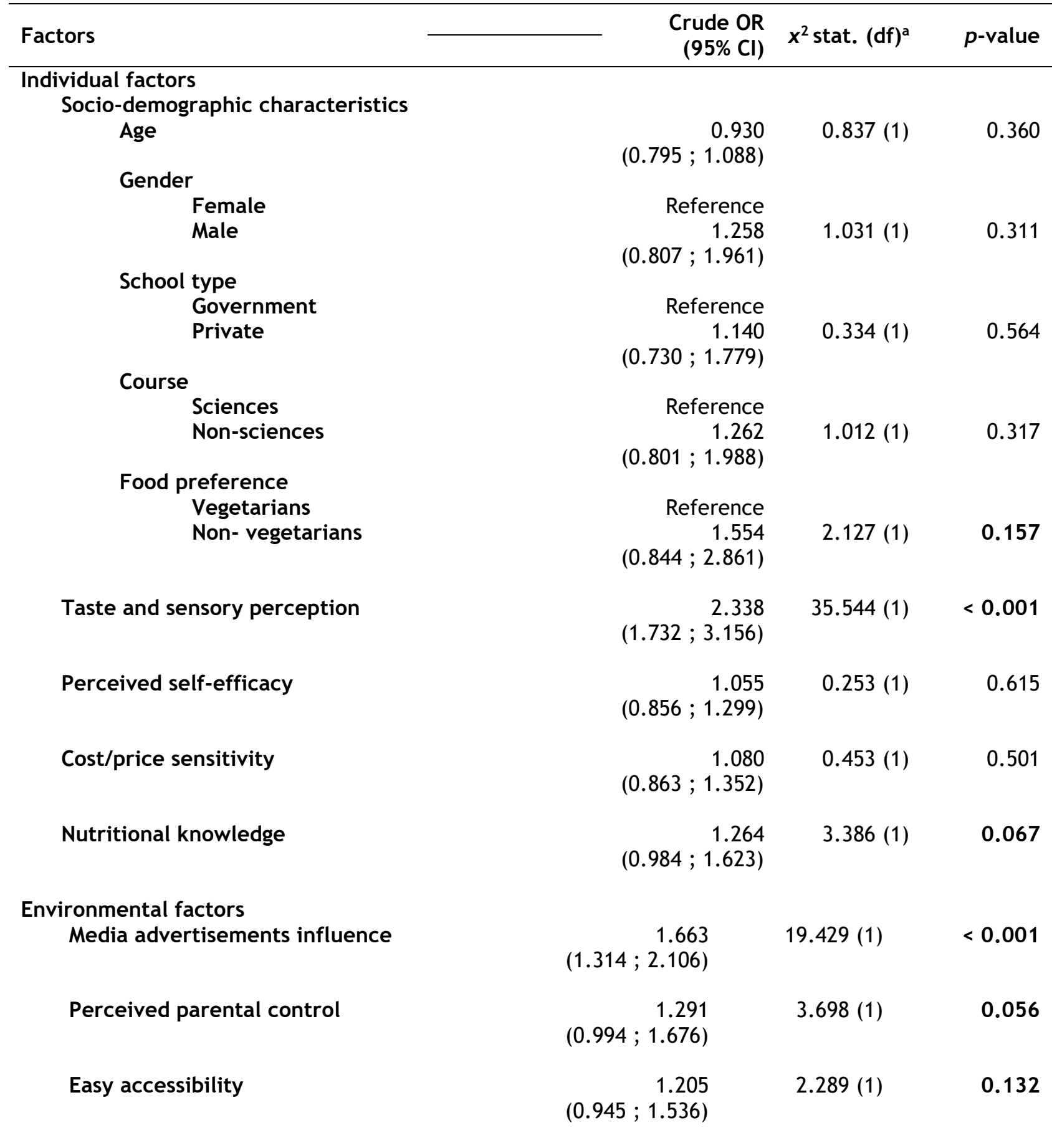

Footnote: $n=$ sample size, $O R=$ Odds Ratio, $\mathrm{Cl}=$ Confidence Interval, $x^{2}$ stat. $=$ Chi-square stat., $d f=d e g r e e s$ of freedom.

a Likelihood Ratio (LR) test

Those variables with $p<0.2$ in simple binary logistic regression were shortlisted into the final model. 
Table 5: Factors associated with unhealthy snacking behaviour. $(n=422)$

\begin{tabular}{|c|c|c|c|c|c|c|}
\hline Factors & B & SE & Wald & df & Sig. & $\begin{array}{r}\text { Adjusted OR } \\
(95 \% \mathrm{Cl})\end{array}$ \\
\hline Taste and sensory perception & 0.789 & 0.180 & 19.259 & 1 & $<0.001$ & $\begin{array}{r}2.202 \\
(1.548 ; 3.133)\end{array}$ \\
\hline Nutritional knowledge & 0.395 & 0.143 & 7.578 & 1 & 0.006 & $\begin{array}{r}1.484 \\
(1.120 ; 1.966)\end{array}$ \\
\hline
\end{tabular}

Footnote: $B$ = the estimated logit coefficient; $S E=$ the standard error of the coefficient; Wald $=[B / S E]^{2} ; \mathrm{Sig}=t$ the significance level of the coefficient; Adjusted $\mathrm{OR}=$ Adjusted Odds Ratio, $\mathrm{Cl}=$ Confidence Interval

Results indicated that the six-predictor model was statistically significant $x^{2}(6, n=422)=47.20, p$ value $<0.001$

Pseudo R-squared statistics:

- $\quad$ Cox \& Snell $R$ Square $=0.106$

- $\quad$ Nagelkerke $R$ Square $=0.157$

Interaction: Wald test for interaction term, $p$-value $>0.05$

Measures of goodness-of-fit:

- Hosmer and Lemeshow Test, $p$-value > 0.05

- Classification tables, $76.8 \%$ of the respondents are correctly classified.

- $\quad A U C=71.9 \%$

\section{Multiple binary logistic regression analysis}

The six-predictor model of unhealthy snacking behaviour was statistically significant $x^{2}(6, n=422)$ $=47.20, \mathrm{p}<0.001$ and explained $15.7 \%$ (Nagelkerke R Square $=0.157$ ) of the total variance of unhealthy snacking behaviour. Furthermore, all possible two-way interactions have examined. Wald test for all interaction terms, $p>0.05$, indicated that no interaction was found. Furthermore, the goodness-of-fit of the overall model was determined by the Hosmer-Lemeshow goodness-of-fit statistic, which was not significant $(p=0.297)$, indicated the dataset fits well with the logistic regression model. The sensitivity, specificity of the final model's prediction were calculated from the classification table. The final model correctly predicted $76.8 \%$ of the respondents whether they practised unhealthy snacking behaviour, which implied the logistic regression model was a good model. Additionally, the discriminatory capacity of the model was evaluated by the area under the receiver operating curve (AUC) analysis, and the result was $71.9 \%$. AUC between $70 \%$ to $80 \%$ indicated the final model was fair to distinguish between those with unhealthy snacking behaviour and those who were not. Table 5 summarises the factors associated with unhealthy snacking behaviour. The result demonstrated that taste-and-sensory perception (Adjusted OR $=2.202$, 95\% Cl [1.548, 3.133], $p<0.001$ ) and nutritional knowledge (Adjusted OR $=1.484,95 \% \mathrm{Cl}[1.120,1.966], p<$ $0.05)$ have a positive association with unhealthy snacking behaviour.

\section{DISCUSSION}

The present study found nearly a quarter (24.6\%) of college students in Kuching practised unhealthy snacking behaviour. In this study, taste-andsensory perception and nutritional knowledge were positively associated with unhealthy snacking behaviour among respondents, whereas other predictors of unhealthy snacking behaviour were not significant. Similarly, the taste-andsensory perception was found to be positively associated with unhealthy snacking behaviour among Norwegian and Persian adolescents in previous studies 22,31 . This is because unhealthy foods were often tasty and associated with a high level of food pleasure ${ }^{32}$. Several studies have demonstrated that taste-and-sensory perception is one of the essential factors in consumers' decision to purchase food ${ }^{33-38}$, and the majority of consumers stated that it was difficult to compromise the taste of food for healthier reasons ${ }^{39}$. Because of adolescents' lack of risk perception of NCDs 20,21, they tended to eat unhealthy snacks because most of these snacks were tasty and immediately satisfied their food pleasure, without considering the health consequences 31,40 . Additionally, nutritional knowledge was also positively associated with unhealthy snacking behaviour among college students in the present study. Evidence showed that, despite understanding the definition of unhealthy snacks and having a certain level of nutritional knowledge, nearly a quarter of Malaysian students engaged in unhealthy snacking behaviour ${ }^{41}$. These young people would rather ignore nutritional knowledge in favour of their eating behaviours and preferences ${ }^{42}$, and their snack choices were commonly influenced by other factors such as convenience, cost, and so on 22,24,43. As a result, research has found that bridging the knowledge-practice gap in nutrition education is a challenge that a shift toward healthy eating behaviours is necessary ${ }^{44}$. Initiatives such as the Integrated School Health Program (ISHP) and KAFE@TEEN that translate knowledge into action/practice could be worthwhile.

\section{Implications for the stakeholders and policymakers}

- College administrators can strengthen the implementation of the ISHP to promote and practice healthy diet habits while prohibiting the sale of unhealthy snacks on the campus. 
- KAFE@TEEN can be used to educate young people about nutrition and to promote healthy eating behaviours. Meanwhile, KAFE@TEEN should encourage young people to put their nutritional knowledge into practice and make healthier snack choices in their daily diet.

- Food-related policymakers shall strengthen the intervention of unhealthy snack companies through food policies. For instance, require them to give commitments to reduce the sugar, fat, and salt content in their products, as well as improve the food labelling.

\section{STUDY LIMITATIONS}

This research was subject to several limitations. First, it was a cross-sectional study. Therefore, the temporal sequence between the factors and unhealthy snacking behaviour was difficult to determine, whereby the results in this study unable to infer causality.

Second, although stratified random sampling was used to select three private colleges and three government colleges in Kuching, the survey was conducted online. Only those who have access to the internet were recruited to participate in this study. Therefore, the sampling biased was a major concern. Non-response biased occurred among the respondents who have no access to the internet because these college students may be inherently different from other respondents. As a result, these results cannot be generalised to the whole Sarawak state as well as the country. However, since the respondents were recruited from six colleges; therefore, the sampling method in this study might be more accurate than cluster sampling for the same sample size in one college.

Third, while the self-administered questionnaire was used as a data collection instrument, the response biased cannot be avoided completely. A one-month recall period was used in this study to determine unhealthy snacking behaviour, which could be influenced by recall bias.

To overcome the limitations of this study in the future, a mixed-mode survey (both online and paper surveys) using the same research questionnaire for college students with and without internet access at home may be required, respectively. Furthermore, using a prospective design with a self-reported snack diary may reduce recall bias ${ }^{45}$.

\section{CONCLUSION}

Unhealthy snacking behaviour among adolescents is a growing public health concern because it is one of the risk factor associated with diet-related NCDs. Nearly a quarter of college students in Kuching practised unhealthy snacking behaviour. According to the findings, college students' nutritional knowledge was not translated into action/practice, and their snack choices were influenced by taste-and-sensory perception.

\section{CONFLICT OF INTEREST DISCLOSURE}

The authors have no conflicts of interest to declare. This research has met the ethical guidelines, adherence to the legal requirements of Malaysia, and received approval from the Ethical Committee of University Malaysia Sarawak, Malaysia.

\section{FUNDING}

No funding was used to support this research and the preparation of the manuscript.

\section{ACKNOWLEDGEMENT}

This study was permitted by the Heads of the selected college to conduct the research. We are grateful to the college students who willingly participated in this study.

\section{ETHICAL ISSUES}

Ethical approval for this research report was obtained by the Ethical Committee of University Malaysia Sarawak (UNIMAS), reference number: UNIMAS/NC-21.02/03-02 Jld.4(48); and the Education Planning and Research Department through the educational research application system (ERAS), reference number: KPM.600$3 / 2 / 3$-eras(6690). Additionally, permission was obtained from the Chairman of Technical and Vocational Education Division, reference number: KPM.600-3/2/3(68), and the Director-General of the Department of Polytechnic and Community College Education Department, Ministry of Higher Education in Putrajaya, reference number: KPT.JPP.PPPP.700-1/1 Jld.12(4).

\section{REFERENCES}

1. Pries $A M$, Filteau $S$, Ferguson EL. Snack food and beverage consumption and young child nutrition in low- and middleincome countries: A systematic review. Matern Child Nutr. 2019;15(S4):e12729.

2. Wansink B, Payne CR, Shimizu M. 'Is this a meal or snack?' Situational cues that drive perceptions. Appetite. 2010 Feb;54(1):214-6.

3. Institute for Public Health. National Health and Morbidity Survey (NHMS) 2017: Adolescent Nutrition Survey [Internet]. Malaysia; 2017. Report No.: NMRR-16-69830042. Available from: http://iku.moh.gov.my/index.php/resea rch-eng/list-of-research-eng/ikueng/nhms-eng/nhms-2017 
4. Hess JM, Jonnalagadda SS, Slavin JL. What Is a Snack, Why Do We Snack, and How Can We Choose Better Snacks? A Review of the Definitions of Snacking, Motivations to Snack, Contributions to Dietary Intake, and Recommendations for Improvement. Adv Nutr. 2016 May 1;7(3):466-75.

5. Potter M, Vlassopoulos A, Lehmann U. Snacking Recommendations Worldwide: A Scoping Review. Adv Nutr. 2018 Mar;9(2):86-98.

6. Murakami K. Nutritional quality of meals and snacks assessed by the Food Standards Agency nutrient profiling system in relation to overall diet quality, body mass index, and waist circumference in British adults. Nutr J. 2017 Sep 13;16(1):57.

7. Bellisle F. Meals and snacking, diet quality and energy balance. Physiol Behav. 2014 Jul 1;134:38-43.

8. O'Connor L, Brage S, Griffin SJ, Wareham NJ, Forouhi NG. The cross-sectional association between snacking behaviour and measures of adiposity: the Fenland Study, UK. Br J Nutr. 2015 Oct;114(8):1286-93.

9. Washington State Department of Health. Healthy Nutrition Guidelines for Vending and Micro-Markets [Internet]. Washington State Department of Health. 2017. Available from: https: / /www.doh.wa.gov/Portals/1/Doc uments/Pubs/140-168-

HealthyNutritionGuidelinesVending.pdf

10. Hess J, Slavin J. Snacking for a cause: nutritional insufficiencies and excesses of U.S. children, a critical review of food consumption patterns and macronutrient and micronutrient intake of U.S. children. Nutrients. 2014 Oct 30;6(11):4750-9.

11. Larson NI, Wall MM, Story MT, NeumarkSztainer DR. Home/family, peer, school, and neighborhood correlates of obesity in adolescents. Obes Silver Spring Md. 2013 Sep;21(9):1858-69.

12. World Health Organisation. WHO EMRO । Unhealthy diet | Causes | NCDs [Internet]. 2020 [cited 2020 Aug 27]. Available from: http://www.emro.who.int/noncommuni cable-diseases/causes/unhealthydiets.html

13. Asghari G, Yuzbashian E, Mirmiran P, Bahadoran Z, Azizi F. Prediction of metabolic syndrome by a high intake of energy-dense nutrient-poor snacks in Iranian children and adolescents. Pediatr Res. 2016 May;79(5):697-704.

14. Ezzati M, Riboli E. Behavioral and Dietary Risk Factors for Noncommunicable Diseases. N Engl J Med. 2013 Sep 5;369(10):954-64.

15. Nickols-Richardson SM, Piehowski KE, Metzgar CJ, Miller DL, Preston AG. Changes in body weight, blood pressure and selected metabolic biomarkers with an energy-restricted diet including twice daily sweet snacks and once daily sugarfree beverage. Nutr Res Pract. 2014 Dec;8(6):695-704.

16. Mithra P, Unnikrishnan B, Thapar R, Kumar N, Hegde S, Mangaldas Kamat A, et al. Snacking Behaviour and Its Determinants among College-Going Students in Coastal South India [Internet]. Vol. 2018, Journal of Nutrition and Metabolism. Hindawi; 2018 [cited 2020 May 24]. p. e6785741. Available from: https://www.hindawi.com/journals/jnm e/2018/6785741/

17. Lewis Gilbert A, McCord AL, Ouyang F, Etter DJ, Williams RL, Hall JA, et al. Characteristics Associated with Confidential Consultation for Adolescents in Primary Care. J Pediatr. 2018 Aug 1;199:79-84.e1.

18. McDonagh JE, Ambresin A-E, Boisen KA, Fonseca $\mathrm{H}$, Kruse PJ, Meynard A, et al. The age of adolescence....and young adulthood. Lancet Child Adolesc Health. 2018 Apr 1;2(4):e6.

19. Deforche B, Van Dyck D, Deliens T, De Bourdeaudhuij I. Changes in weight, physical activity, sedentary behaviour and dietary intake during the transition to higher education: a prospective study. Int J Behav Nutr Phys Act. 2015 Feb 15;12(1):16.

20. World Health Organisation. Coming of age: Adolescent health [Internet]. 2020 [cited 2020 May 5]. Available from: https: / /www.who.int/healthtopics/adolescents/coming-of-ageadolescent-health

21. Vanhecke TE, Miller WM, Franklin BA, Weber JE, McCullough PA. Awareness, knowledge, and perception of heart disease among adolescents. Eur J 
Cardiovasc Prev Rehabil. 2006 Oct 1;13(5):718-23.

22. Yazdi Feyzabadi V, Keshavarz Mohammadi $\mathrm{N}$, Omidvar N, Karimi-Shahanjarini A, Nedjat S, Rashidian A. Factors Associated With Unhealthy Snacks Consumption Among Adolescents in Iran's Schools. Int J Health Policy Manag. 2017 Sep 1;6(9):51928.

23. Story M, Neumark-sztainer D, French S. Individual and Environmental Influences on Adolescent Eating Behaviors. J Am Diet Assoc. 2002 Mar 1;102(3, Supplement):S40-51.

24. Larson N, Miller JM, Eisenberg ME, Watts AW, Story M, Neumark-Sztainer D. Multicontextual correlates of energydense, nutrient-poor snack food consumption by adolescents. Appetite. 2017 May 1;112:23-34.

25. Ursachi G, Horodnic IA, Zait A. How Reliable are Measurement Scales? External Factors with Indirect Influence on Reliability Estimators. Procedia Econ Finance. 2015;20:679-86.

26. Tabachnick BG, Fidell LS. Using multivariate statistics Boston. MA Allyn Bacon. 2007;5:2007.

27. Box GEP, Tidwell PW. Transformation of the Independent Variables.

Technometrics. 1962 Nov 1;4(4):531-50.

28. Sarkar SK, Midi H. Multicollinearity Problems and Remedies in Binary Logistic Regression. Res Bull Inst Math Res. 2010;3(2):27-34.

29. Field A. Discovering Statistics Using IBM SPSS Statistics. SAGE; 2013. 953 p.

30. Norušis MJ. SPSS 14.0 Guide to Data Analysis. Prentice Hall; 2006. 676 p.

31. Wang Q, Oostindjer M, Amdam GV, Egelandsdal B. Snacks With Nutrition Labels: Tastiness Perception, Healthiness Perception, and Willingness to Pay by Norwegian Adolescents. J Nutr Educ Behav. 2016 Feb 1;48(2):104-111.e1.

32. Drewnowski A. Energy Density, Palatability, and Satiety: Implications for Weight Control. Nutr Rev. 1998;56(12):347-53.
33. Connors M, Bisogni CA, Sobal J, Devine CM. Managing values in personal food systems. Appetite. 2001 Jun;36(3):189-200.

34. Drewnowski A, Rock CL. The influence of genetic taste markers on food acceptance. Am J Clin Nutr. 1995 Sep 1;62(3):506-11.

35. Glanz K, Basil M, Maibach E, Goldberg J, Snyder D. Why Americans eat what they do: taste, nutrition, cost, convenience, and weight control concerns as influences on food consumption. J Am Diet Assoc. 1998 Oct;98(10):1118-26.

36. Kearney M, Kearney J, Dunne A, Gibney M. Sociodemographic determinants of perceived influences on food choice in a nationally representative sample of Irish adults. Public Health Nutr. 2000 Jun;3(2):219-26.

37. Mok LW. The Effect of Variety and Dietary Restraint on Food Intake in Lean Young Women: A Preliminary Study. J Gen Psychol. 2009 Dec 21;137(1):63-83.

38. Kourouniotis $S$, Keast RSJ, Riddell LJ, Lacy K, Thorpe MG, Cicerale S. The importance of taste on dietary choice, behaviour and intake in a group of young adults. Appetite. 2016 01;103:1-7.

39. Ballco P, Caputo V, de-Magistris T. Consumer valuation of European nutritional and health claims: Do taste and attention matter? Food Qual Prefer. 2020 Jan;79:103793.

40. Teo YB, Sedek R. Association between snacking patterns, energy and nutrient intakes, and body mass index among school adolescents in Kuala Lumpur. In 2012.

41. Hoque KE, Kamaluddin MA, Razak AZA, Wahid AAA. Building healthy eating habits in childhood: a study of the attitudes, knowledge and dietary habits of schoolchildren in Malaysia. PeerJ. 2016 Nov 24;4:e2651.

42. Onurlubaş E, Yilmaz N. Fast food consumption habits of university students. J Food Agric Environ. 2013 Jan 1;11:12-4.

43. Azman SAM, Ibrahim MA, Azahari N. Knowledge, attitude and practice on fast food consumption among normal and overweight/obese International Islamic University Malaysia Kuantan students. Int $J$ Allied Health Sci. 2020 Dec 23;4(3):1189-202. 
44. Sherman J, Muehlhoff E. Developing a nutrition and health education program for primary schools in Zambia. J Nutr Educ Behav. 2007 Dec;39(6):335-42.
45. Cleobury L, Tapper K. Reasons for eating 'unhealthy' snacks in overweight and obese males and females. J Hum Nutr Diet. 2014 Aug;27(4):333-41. 